\title{
Heat pump capacity effects on peak electricity consumption and total length of self- and solar-assisted shallow ground heat exchanger networks
}

\author{
Parham Eslami Nejad
}

\author{
Massimo Cimmino
}

\author{
Sophie Hosatte-Ducassy
}

\begin{abstract}
A new "self-assisted" Ground Source Heat Pump (GSHP) system configuration is proposed to address the relatively bigh peak electricity demand of undersized GSHP systems equiped with auxiliary electric heater. In this configuration, ground heat exchangers (GHE) have two independent circuits: the first circuit is used to inject the extra heat produced by the heat pump into the ground during off-peak operations, while the second circuit is used to extract heat in the winter and reject heat in the summer for space heating and cooling, respectively. This configuration is compared against a "solar-assisted" configuration and a conventional single U-tube configuration. An analytical model for shallow GHE networks is used to evaluate the effects of the heat pump nominal capacity and the borehole total length on the total electricity consumption and peak electricity demand of the three configurations. Results show that the self-assisted configuration reduces the peak electricity demand by 47\%, in a case with a 29\% undersized GHE network and a $16 \%$ undersized heat pump nominal capacity, while it increases the total energy consumption by $4.1 \%$. Using a solar-assisted configuration for the same sizing parameters reduces the peak electricity demand by only $6.3 \%$ and the total energy consumption by $3.8 \%$.
\end{abstract}

\section{INTRODUCTION}

Ground source heat pump (GSHP) systems offer significant energy saving potential in cold climates because of their relatively good seasonal performance in both heating and cooling applications. However, due to their high initial costs, the most expensive system components (e.g. heat pumps and GHEs) are often deliberately undersized, leading to higher peak electricity demands in comparison to other market available heating and cooling systems. A so-called solar-assisted alternative, which integrates solar thermal technologies with GSHP systems, has been shown to decrease the negative impacts of undersized heat pump nominal capacity and borehole length in cold climates (Kjellsson, et al. 2010; Chiasson and Yavuzturk 2003; Han et al. 2008). Among several possible approaches, the direct injection of available solar heat into the ground using shared boreholes has been favored in several recent studies due to its simplified system integration (Eslami Nejad and Bernier 2011; Belzile, et al. 2016).

However, solar-assisted geothermal heat pumps suffer from the fact that heat can only be stored into the ground when solar thermal energy is available, which may differ from the time of peak heating loads. Additionnaly, large amounts of solar thermal energy are required to achieve savings in terms of GHE size. To diminish these shortcomings, a "self-assisted" GSHP configuration is examined. This configuration uses the heat pump to store surplus heat into the field of GHEs through a secondary fluid loop. The effects of heat pump nominal capacity and total borehole length on

Parham Eslami Nejad is a research scientist at Natural Resources Canada, CanmetENERGY, Massimo Cimmino (massimo.cimmino@polymtl.ca) is a postdoctoral fellow in the department of mechanical engineering at McGill university and Sophie Hosatte-Ducassy is the director of the Buildings Group of CanmetENERGY, Natural Resources Canada. 
the the electricity consumption and peak electricity demand are evaluated for the case of a single family detached home located in Montreal. The newly proposed self-assisted configuration is compared against the solar-assisted and conventional single U-tube configurations for four different cases: Case 1 with properly sized borehole network and heat pump capacity, Case 2 with reduced heat pump nominal capacity, Case 3 with shortened borehole network, and Case 4 with combined undersized borehole network and heat pump nominal capacity.

\section{SYTEM DESCRIPTION}

The seasonal performance of three configurations, self-assisted, solar-assisted and conventional configurations, is assessed under given space heating and cooling load profiles for a $210 \mathrm{~m}^{2}$ single family detached home located in Montreal. Figure 1 presents the building load (left), the annual outdoor temperature profile (center) and the total tilted solar radiation on solar collectors (right) taken from a TMY2 (National Solar Radiation Data Base) weather file for Montreal. The peak hourly building load is $14.18 \mathrm{~kW}$ and $4.21 \mathrm{~kW}$ for heating and cooling respectively. Annual space heating and cooling requirements are $29266 \mathrm{kWh}$ and $1682 \mathrm{kWh}$ respectively. More details about the building model and validation are found in Kegel et al. (2012a, 2012b). The same outdoor temperatures, solar radiation and building loads are used for every year of the simulations.
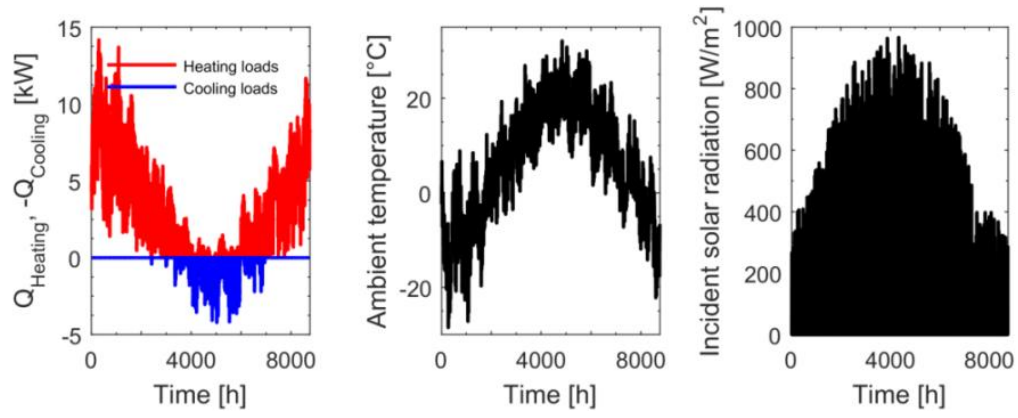

Figure 1 Building loads (left), ambient temperature (center) and incident solar radiation (right)

In all configurations, the heating and cooling system consists of a geothermal heat pump connected to an array of $25(5 \times 5)$ ground heat exchangers in a zig-zag pattern, as shown in Figure 2. When used, Circuit 2 (shown in red) has the heat carrier fluid flowing in opposite direction to Circuit 1 (shown in blue). Auxiliary heating is provided by an electric auxiliary heating system when the heat pump capacity is insufficient to cover the building heating loads. Two heat pumps with nominal capacities of $15.2 \mathrm{~kW}$ and $12.7 \mathrm{~kW}$ are considered. The variation of the heat pump capacities and the coefficient of performance with regards to entering fluid temperature are presented in Figure 3.
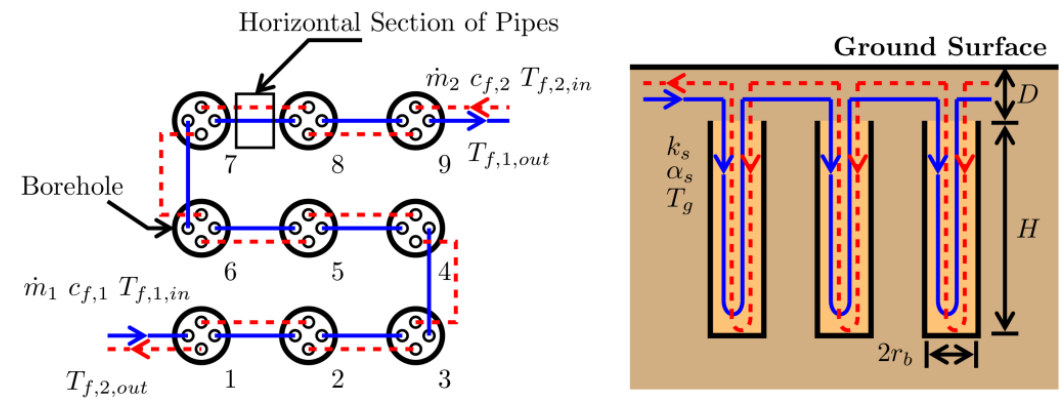

Figure 2 Sample zig-zag patern for a field of $3 \times 3$ boreholes 

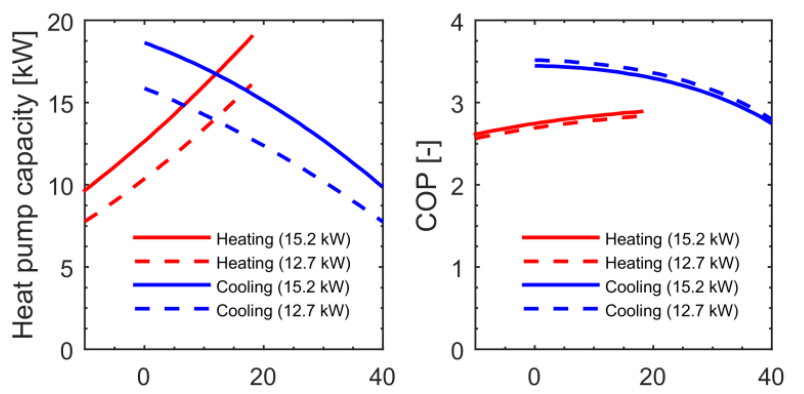

Entering fluid temperature $\left[{ }^{\circ} \mathrm{C}\right]$ Entering fluid temperature $\left[{ }^{\circ} \mathrm{C}\right]$

Figure 3 Heat pump capacity and COP as a function of entering fluid temperature

For all cases considered, the spacing between boreholes is $B=2 \mathrm{~m}$. The boreholes have a radius $r_{b}=0.042 \mathrm{~m}$ and are buried at a distance $D=1 \mathrm{~m}$ below the ground surface. U-tube pipes have an inner radius $r_{p, i}=0.0164 \mathrm{~m}$, an outer radius $r_{p, o}=0.0167 \mathrm{~m}$ and are equally spaced at a distance $D_{s}=0.024 \mathrm{~m}$ from the center of the boreholes. The thermal conductivities of the ground, the grout and the pipes are $k_{s}=2.65 \mathrm{~W} / \mathrm{m}-\mathrm{K}, k_{b}=1 \mathrm{~W} / \mathrm{m}-\mathrm{K}$ and $k_{p}=0.4 \mathrm{~W} / \mathrm{m}-\mathrm{K}$, respectively. The ground thermal diffusivity is $\alpha_{s}=0.08 \mathrm{~m}^{2} /$ day. The fluid flow rate is $\dot{m}_{1}=\dot{m}_{2}=0.5 \mathrm{~kg} / \mathrm{s}$ in both circuits, when applicable, with a fluid specifc heat of $4000 \mathrm{~J} / \mathrm{kg}-\mathrm{K}$ (propylene-glycol 20\%) and a fluid convection coefficient of $1500 \mathrm{~W} / \mathrm{m}^{2}-\mathrm{K}$. The minimum allowed fluid temperature is $T_{f, \min }=-2^{\circ} \mathrm{C}$ in all cases. The borehole length $H$ and the nominal heat pump capacity vary from case to case.

\section{Conventional Configuration}

The first system is a conventional ground source heat pump system, which provides a base of comparison for the other two systems proposed in this paper. In this system, the heat pump is connected to single U-tube vertical boreholes (Figure 4a). The heat pump covers both the heating and cooling loads. Auxiliary electric heating is used when the heat pump capacity is insufficient.
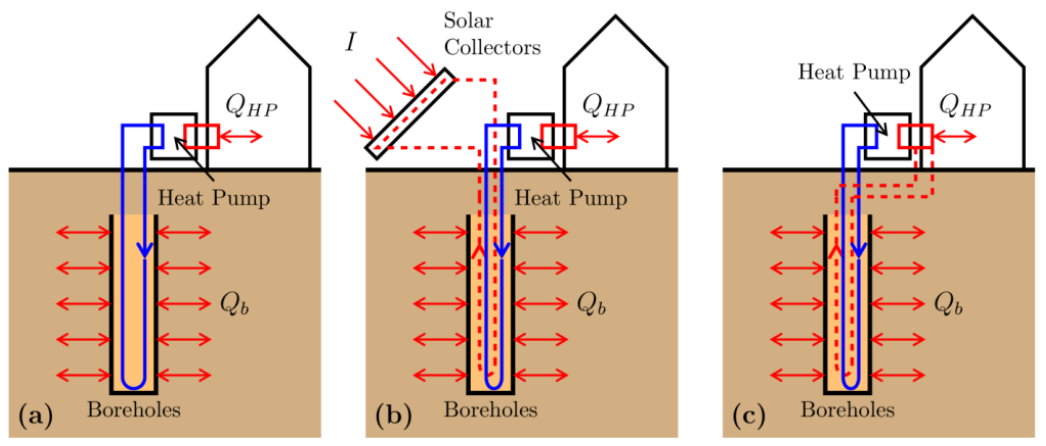

Figure 4 Schematic of (a) conventional GSHP, (b) solar assisted GSHP, and (c) self-assisted GSHP systems

At all times when the heat pump is operating, the total heat extraction rate (positive for extraction, negative for injection) from the borehole (via Circuit 1) is given by the heat pump performance data based on the outlet fluid temperature from the borefield: 


$$
Q_{\text {circuit }, 1}= \begin{cases}\min \left(Q_{\text {Heating }}, C A P_{\text {Heating }}\right) \cdot \frac{C_{\text {Heating }}-1}{C O P_{\text {Heating }}} & \text { Heating mode } \\ -\min \left(Q_{\text {Cooling }}, C A P_{\text {Cooling }}\right) \cdot \frac{C O P_{\text {Cooling }}+1}{C O P_{\text {Cooling }}} & \text { Cooling mode }\end{cases}
$$

where $Q_{\text {circuit, } 1}$ is the total heat extraction rate from the heat pump ciurcuit, $Q_{H e a t i n g}$ and $Q_{\text {Cooling }}$ are the building heating and cooling loads, $C A P_{\text {Heating }}$ and $C A P_{\text {Cooling }}$ are the heat pump heating and cooling capacities and $C O P_{\text {Heating }}$ and $C O P_{\text {Cooling }}$ are the heat pump coefficients of performance in heating and cooling modes.

\section{Solar-Assisted Configuration}

The solar-assisted configuration is equipped with double U-tube vertical boreholes (two circuits). Circuit 1 is connected to the heat pump while Circuit 2 is connected to the solar collectors (Figure 4b). Via Circuit 2, solar heat is injected into the ground at all times when it is available. In heating dominated climates, where the ground temperature typically decreases due to unbalanced loads, this helps to increase the ground temperature and store heat in the borefield. Using Circuit 1, the heat pump meets the space heating and cooling loads, as in the conventional GSHP system. Auxiliary heat is used when the heat pump heating capacity is insufficient. Circuit 2 is connected to an array of solar collectors with total area $A_{c o l}=5 \mathrm{~m}^{2}$. The collector efficiency $\eta$ varies with the ambient temperature $T_{a}$, the outlet fluid temperature from the borefield (and into the solar collectors) $T_{f, 2, o u t}$, and the incident solar radiation $I$ :

$$
\begin{aligned}
& Q_{\text {circuit }, 2}=-\eta A_{c o l} \cdot I \\
& \eta=F_{R}-a \frac{T_{f, 2, o u t}-T_{a}}{I}
\end{aligned}
$$

where $Q_{\text {circuit }, 2}$ is the total heat extracted from Circuit 2 (negative for heat injection), $F_{R}=0.86$ is the collector heat removal factor and $a=5.33$ is a parameter associated with the heat losses of the collector to the ambient air.

\section{Self-Assisted Configuration}

Double U-tube vertical boreholes are also used in the self-assisted configuration. However, Circuit 2 is only used during the colder winter months, at certain selected periods prior to peak heating conditions when extra heat produced by the heat pump is available to be injected into the ground (Figure 4c). The time period of injection before the peak is determined using simulations to minimize (i) the peak electricity demand and (ii) the heat pump energy consumption for the configuration. Heat injection will increase the ground temperature and store heat in the cluster of shallow boreholes, which may lead to an increase in heat pump capacity during peak conditions and, therefore, lower peak electricity demands.

As in the other configurations, Circuit 1 is connected to the heat pump. However, in this case Circuit 2 is connected to the condenser of the heat pump on the building side. Even though in reality the heat pump system would cycle between heat extraction and self-assisted modes, the two processes are treated as simultaneous in the simulations due to the time step of 1 hour. Whenever the self-assisted mode is allowed, Circuit 2 is used to inject heat into the ground if there is more than $20 \%$ of the heat pump capacity leftover after satisfying the building loads. The total rates of heat extraction in Circuits 1 and 2 are given by:

$$
Q_{\text {circuit }, 1}= \begin{cases}\min \left(Q_{\text {Heating }}, C A P_{\text {Heating }}\right) \cdot \frac{C O P_{\text {Heating }}-1}{C O P_{\text {Heating }}} & \text { if } Q_{\text {Heating }} \geq 0.8 C A P_{\text {Heating }} \\ C A P_{\text {Heating }} \cdot \frac{C O P_{\text {Heating }}-1}{C O P_{\text {Heating }}} & \text { if } Q_{\text {Heating }}<0.8 C A P_{\text {Heating }}\end{cases}
$$




$$
Q_{\text {circuit }, 2}= \begin{cases}0 & \text { if } Q_{\text {Heating }} \geq 0.8 C A P_{\text {Heating }} \\ \left(C A P_{\text {Heating }}-Q_{\text {Heating }}\right) \cdot \frac{C O P_{\text {Heating }}-1}{C O P_{\text {Heating }}} & \text { if } Q_{\text {Heating }}<0.8 C A P_{\text {Heating }}\end{cases}
$$

\section{SIMULATION MODEL}

The ground-source heat pump (GSHP) system is simulated using the simulation model of Cimmino and EslamiNejad (2016). Boreholes and horizontal sections of pipes are modeled as finite line sources with uniform heat extraction rates. The borehole wall and horizontal section of pipe temperatures are obtained from the spatial and temporal superpositions of the finite line source (FLS) solution for all boreholes and horizontal sections of pipes. The load aggregation algorithm of Claesson and Javed (2012) is used for the temporal superposition of heat extraction rates. Outlet fluid temperatures are calculated from the inlet fluid temperatures and borehole wall temperatures based on analytical solutions for double U-tube boreholes (Eslami-Nejad and Bernier 2011) when both circuits are active, and single U-tube boreholes (Hellström 1991) when only one is active. The heat pump coefficient of performance (COP), capacity and power consumption are loaded from external data files. Ground surface effects are considered by using a correlation (Badache et al. 2016) for the calculation of the ground temperature at $z=D$ for horizontal sections of pipes and for the calculation of the average ground temperature over $D \leq z \leq D+H$ for boreholes.

The simulation model of Cimmino and Eslami-Nejad (2016) was modified to account for the minimum operating fluid temperature $T_{f, m i n}$. Auxiliary heating is used instead of the heat pump if the inlet fluid temperature into the borefield would fall below the minimum temperature by using the heat pump. In these cases, the total heat extraction rate from Circuit 1 is set to zero. At each simulation time step, the simulation model follows this sequence:

1. Calculate aggregated heat extraction rates from previous time steps.

2. Evaluate ground temperatures from correlations.

3. Read building heating and cooling loads and meteorological data from external files.

4. Evaluate the total heat extraction rate from Circuit 1 based on the building load and the values of the heat pump COP and the heat pump capacity calculated based on instant value of returning fluid temperature.

5. Evaluate the total heat extraction rate from Circuit 2:

a. In the solar-assisted configuration, if solar radiation is available (i.e. $Q_{\text {circuit, } 2}<0$ ), evaluate the total heat extraction rate based on the solar collector efficiency and the current value of returning temperature.

b. In the self-assisted configuration, the total heat extraction rate is calculated from the remaining heat pump capacity.

6. Calculate borehole wall and fluid temperatures from the FLS model and borehole analytical solutions respectively.

7. Evaluate auxiliary heating power:

a. If inlet fluid temperature $T_{f, 1, i n}$ into Circuit 1 is above the minimum allowed fluid temperature $T_{f, \min }$, then auxiliary heating power is the difference between the building load and the heat pump capacity.

b. If inlet fluid temperature $T_{f, 1, i n}$ into Circuit 1 is below the minimum allowed fluid temperature $T_{f, \min }$, then auxiliary heating power is equal to the building load and the total heat extraction rate is set to 0 .

8. Re-evaluate heat pump COP, capacity and power consumption and re-calculate fluid and borehole wall temperatures and auxiliary heating power until convergence is reached.

\section{RESULTS}

In this study, the peak electricity demand and the total electricity consumption of the systems are compared for different borehole lengths and two distinct nominal heat pump capacities in hourly simulations over a period of 5 years. Four cases are selected to investigate the effect of heat pump nominal capacity and borehole length. For Case 1 and Case 2, boreholes are sized adequately and the solar-assisted and conventional configurations are compared under 
different heat pump sizes. In Case 3, the borehole length is undersized by $19 \%$ and the heat pump size is kept unchanged. In Case 4 , the borehole length and heat pump nominal capacity are undersized by $29 \%$ and $16 \%$, respectively. The selfassisted configuration is investigated only in Cases 3 and 4 since under properly sized borehole cases (Cases 1 and 2), this configuration does not show any benefits.

\section{Case 1}

In Case 1, the length of each borehole and the nominal capacity of the heat pump are determined so that almost no auxiliary energy input is needed for both the solar-assisted and conventional GSHP systems (Table 1 and Figure 5). Based on the annual simulation, each borehole has a length of $21 \mathrm{~m}$ (Table 1) and the heat pump nominal capacity is $15.2 \mathrm{~kW}$. In this case, solar injection in the solar-assisted configuration has a negligible effect on the fifth-year energy consumption $(0.35 \%)$ despite significant heat injection $(\sim 6000 \mathrm{kWh})$ into the ground (Table 1: Case 1). Since auxiliary heating is concentrated in the first few months, energy consumption will only be shown for the first 3 months of the fifth simulation year in subsequent cases.

Table 1. Simulation Results of Case 1 and Case 2

\begin{tabular}{|c|c|c|c|c|c|}
\hline \multirow[b]{2}{*}{ Result metric } & \multirow[b]{2}{*}{ Units } & \multicolumn{2}{|c|}{ Case 1} & \multicolumn{2}{|c|}{ Case 2} \\
\hline & & Conventional & Solar Assisted & Conventional & Solar Assisted \\
\hline Borehole length & $(\mathrm{m})$ & 21 & 21 & 21 & 21 \\
\hline Heat pump capacity & $(\mathrm{kW})$ & 15.2 & 15.2 & 12.7 & 12.7 \\
\hline Minimum returning fluid temperature & $\left({ }^{\circ} \mathrm{C}\right)$ & -1.78 & -1.02 & -0.72 & -0.19 \\
\hline Total energy consumption (year 5) & (kWh) & 10962 & 10923 & 11224 & 11167 \\
\hline Reduction relative to case 1 (conventional) & $(\%)$ & 0 & 0.35 & -2.39 & -1.87 \\
\hline Auxiliary heating (year 5) & (kWh) & 1.18 & 0 & 110 & 78.9 \\
\hline Peak energy demand & $(\mathrm{kW})$ & 5.29 & 5.07 & 6.85 & 6.63 \\
\hline Heat injected into ground (year 5) & (kWh) & 2173 & 8248 & 2165 & 8234 \\
\hline Heat extracted from ground (year 5) & (kWh) & 18792 & 18834 & 18515 & 18576 \\
\hline
\end{tabular}

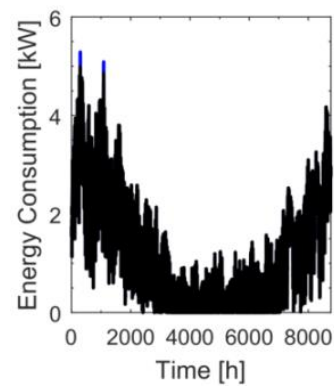

Figure 5 Energy consumption of the conventional (left) and solar-assisted (right) configurations during year 5 for Case 1
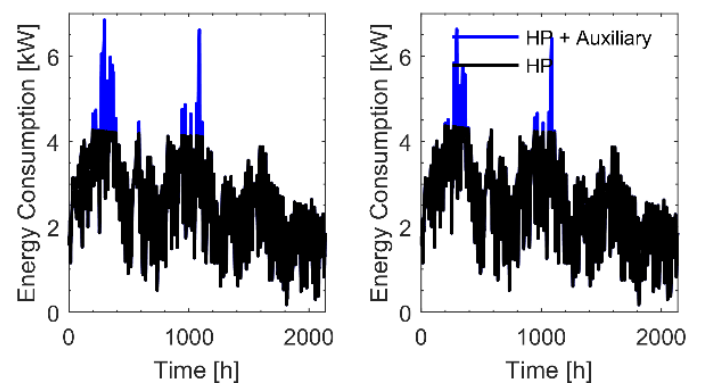

Figure 6 Energy consumption of the conventional (left) and solar-assisted (right) configurations during the first 3 months of year 5 for Case 2

\section{Case 2}

The same borehole length is used in Case 2 with a reduced heat pump nominal capacity $(12.7 \mathrm{~kW})$. In this case, the total energy consumption during the fifth year increased by $2.4 \%$ and $1.9 \%$ for conventional and solar-assisted configurations, respectively, compared to the conventional configuration in Case 1 (Table 1). Peak energy demand increased by almost $1.5 \mathrm{~kW}$ compared to Case 1 (Figures 5 and 6). Similar to Case 1, despite significant solar heat injection into the ground, both the total energy use and peak energy demand reductions are very marginal $(0.5 \%$ and $3.2 \%$, respectively, compared to the conventional configuration of the same case). 


\section{Case 3}

In Case 3, shorter boreholes (17 $\mathrm{m}$ each) are used in combination with an adequately sized heat pump (15.2 $\mathrm{kW})$. For the self-assisted configuration, heat pump capacity (beyond what is required to meet the space heating loads) is injected into the ground for 18 days prior to peak heating conditions on February 15th (Figure 7, right, red line). This time period was selected based on exploratory simulations so that auxiliary heating is used only marginaly throughout the heating season. The solar assisted case followed the same control sequence as in the previous cases. Results show that the solar-assisted and self-assisted configurations decreased the peak energy demand by $0.8 \%$ and $59 \%$, respectively, compared to the conventional configuration (Table 2: Case 3). Furthermore, the self-assisted configuration requires almost no auxiliary heating. However, it increased the fifth-year energy consumption by $6.4 \%$ due to increased heat pump energy use during off-peak operations. The solar-assisted configuration decreased the energy consumption during the fifth year by $1.8 \%$ (Table 2: Case 3).
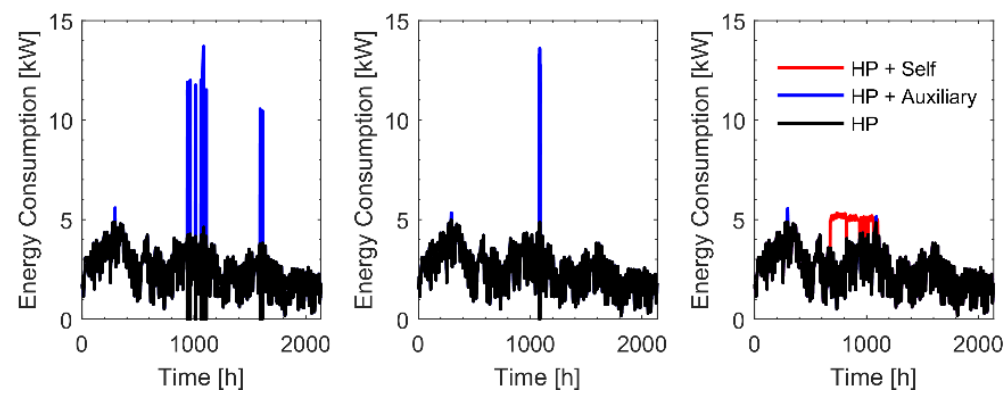

Figure 7 Energy consumption of the conventional (left), solar-assisted (center) and self-assisted (right) configurations during the first 3 months of year 5 for Case 3
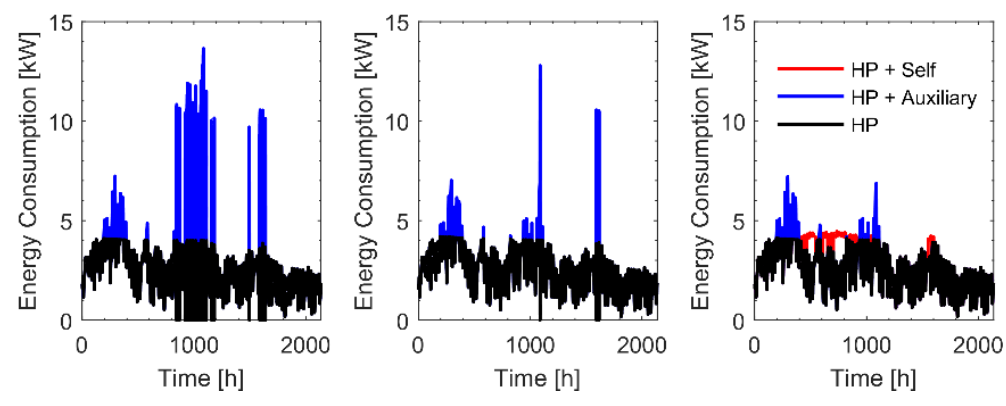

Figure 8 Energy consumption of the conventional (left), solar-assisted (center) and self-assisted (right) configurations during the first 3 months of year 5 for Case 4

\section{Case 4}

In Case 4, both the borehole network and the heat pump are selected to be smaller than that of the base case (Case 1). Each borehole is $15 \mathrm{~m}$ long (29\% reduction relative to the base case) and the heat pump nominal capacity is $12.7 \mathrm{~kW}$. For the self-assisted configuration, excess heat pump capacity (above what is required for building heating loads) is injected into the ground during two periods; (i) for 29 days prior to February $15^{\text {th }}$ and (ii), for 2 days prior to 
March $7^{\text {th }}$ (Figure 8, right, red line). As in Case 3, this time period was selected so that auxiliary heating is used only marginaly throughout the heating season. A significant reduction of the peak energy demand has been calculated $(47 \%)$ for the self-assisted configuration, while the peak is reduced by only $6.3 \%$ using the solar-assisted configuration (Table 2: Case 4) despite significant solar thermal energy injection into the bore field when compared to the conventional and self-assisted configurations. The solar-assisted configuration decreases the fifth-year energy consumption by $3.8 \%$ while the results for the self-assisted configuration show an increase of $4.1 \%$ compared to the conventional configuration. The energy consumption increase of the self-assisted configuration is mainly due to more frequent heat pump operations during off-peak hours as the auxiliary heat is consumed equally in both configurations (182 kWh in Table 2: Case 4).

Table 2. Simulation Results of Case 3 and Case 4

\begin{tabular}{|c|c|c|c|c|c|c|c|}
\hline & & & Case 3 & & & Case 4 & \\
\hline Result metric & Units & Conv. & $\begin{array}{l}\text { Solar } \\
\text { Assis. }\end{array}$ & Self Assis. & Conv. & $\begin{array}{l}\text { Solar } \\
\text { Assis. }\end{array}$ & Self Assis. \\
\hline Borehole length & (m) & 17 & 17 & 17 & 15 & 15 & 15 \\
\hline Heat pump capacity & $(\mathrm{kW})$ & 15.2 & 15.2 & 15.2 & 12.7 & 12.7 & 12.7 \\
\hline Minimum returning fluid temperature & $\left({ }^{\circ} \mathrm{C}\right)$ & -2.00 & -1.99 & -1.98 & -2.00 & -2.00 & -1.99 \\
\hline Auxiliary heating (year 5) & $(\mathrm{kWh})$ & 295 & 41.1 & 3.56 & 831 & 182 & 182 \\
\hline Peak energy demand & $(\mathrm{kW})$ & 13.70 & 13.59 & 5.55 & 13.64 & 12.78 & 7.21 \\
\hline Heat injected into ground (year 5) & $(\mathrm{kWh})$ & 2173 & 8257 & 3817 & 2166 & 8244 & 3738 \\
\hline Heat extracted from ground (year 5) & $(\mathrm{kWh})$ & 18573 & 18780 & 18779 & 18005 & 18461 & 18432 \\
\hline
\end{tabular}

\section{CONCLUSION}

In this study, a shallow ground heat exchanger network is connected to a heat pump to satisfy space heating and cooling of a single family residential building located in a cold climate. The effect of the heat pump and the GHE sizes on the total electricity use and peak electricity demand of the system was investigated for three different configurations. A new "self-assisted" configuration is compared to a solar-assisted and a conventional GSHP system.

Under a properly sized shallow borehole network, it is shown that the solar-assisted GSHP system does not noticeably reduce the total energy use or the peak energy demand. However, it improves the system energy consumption for an undersized borehole network. The self-assisted configuration can significantly lower the peak electricity demand and use of auxiliary heating when the borehole network is undersized, but it increases the heat pump energy consumption. In the presented Cases 3 and 4 , the peak energy demand was reduced by $59 \%$ and $47 \%$ while the total energy consumption increased by $6.4 \%(710 \mathrm{kWh})$ and $4.1 \%(480 \mathrm{kWh})$ when compared to the corresponding conventional system. Case 4 has thus shown that appreciable peak energy demand reduction can be achieved at relatively low energy costs. Overall, significant borehole length and heat pump size reduction can be envisioned using self-assisted configuration. However, the presented self-assisted geothermal heat pump system relies on the prediction of the time of the peak heating load. Proper control strategies, such as model predictive control, should then be envisioned for this system and will be addressed in future work.

\section{ACKNOWLEDGMENTS}

This work was financially supported by the ecoENERGY Innovation Initiative program (Natural Resources Canada) and the Fonds de Recherche du Québec - Nature et Technologies (FRQNT). 


\section{REFERENCES}

Badache, M., P. Eslami-Nejad, M. Ouzzane, Z. Aidoun and L. Lamarche. 2016. A new modeling approach for improved ground temperature profile determination. Renewable Energy 85: 436-444.

Belzile, P., L. Lamarche and D.R. Rousse. 2016. Geothermal heat exchange in boreholes with independent sources. Applied Thermal Engineering 98: 1221-1230.

Chiasson, A.D. and C. Yavuzturk. 2003. Assessment of the viability of bybrid geothermal heat pump systems with solar thermal collectors. ASHRAE Transactions 109 (2): 487-500.

Cimmino, M. and P. Eslami Nejad. 2016. A simulation model for solar assisted shallow ground heat exchangers in series arrangement. Energy and Buildings. In press.

Claesson, J. and S. Javed. 2011. An analytical method to calculate borehole fluid temperatures for time-scales from minutes to decades. ASHRAE Transactions 117(2): 279-288.

Eslami nejad, P. and M. Bernier. 2011. Coupling of geothermal heat pumps with thermal solar collectors using double U-tube borehole with two independent circuits. Applied Thermal Engineering 31(14-15): 3066-3077.

Han, Z., M. Zheng, F. Kong, F. Wang, Z. Li and T. Bai. 2008. Numerical simulation of solar assisted ground-source heat pump heating system with latent heat energy storage in severely cold area. Applied Thermal Engineering 28 (11-12): 1427-1436.

Hellström, G. 1991. Ground heat storage, thermal analysis of duct storage system. Doctoral Thesis, University of Lund, Sweden (1991).

Kjellsson, E., G. Hellström and B. Perers. 2010. Optimization of systems with the combination of ground-source heat pump and solar collectors in dwellings. Energy 35(6): 2667-2673.

Kegel, M., J. Tamasauskas, R. Sunye and A. Langlois. 2012a. Assessment of a Solar Assisted Air Source and a Solar Assisted Water Source Heat Pump System in a Canadian Household. Energy Procedia 30: 654-663.

Kegel, M., R. Sunye and J. Tamasauskas. 2012b. Life cycle cost comparison and optimization of different heat pump systems in the Canadian climate. Proceedings of eSim: 492-505.

National Solar Radiation Data Base, web address: http://sel.me.wisc.edu/trnsys/weather/tmy2data.htm 